Article

\title{
Evaluation of the Reference Numerical Parameters of the Monthly Method in ISO 13790 Considering S/V Ratio
}

\section{Hee-Jeong Kwak ${ }^{1}$, Jae-Hun Jo ${ }^{2, *}$ and Seung-Jik Suh ${ }^{2, *}$}

1 Green Building Research Division, Korea Institute of Civil Engineering and Building Technology, Gyeonggi 411-712, Korea; E-Mail: khj0927@kict.re.kr

2 Department of Architectural Engineering, Inha University, Incheon 402-751, Korea

* Authors to whom correspondence should be addressed; E-Mails: jhjo@inha.ac.kr (J.-H.J.); energeti@inha.ac.kr (S.-J.S.); Tel.: +86-32-860-7582 (J.-H.J.); +86-32-860-7590 (S.-J.S.); Fax: +82-32-866-4624 (J.-H.J.); +82-32-866-4624 (S.-J.S.).

Academic Editor: Derek Clements-Croome

Received: 6 December 2014 / Accepted: 5 January 2015 / Published: 12 January 2015

\begin{abstract}
Many studies have investigated the accuracy of the numerical parameters in the application of the quasi steady-state calculation method. The aim of this study is to derive the reference numerical parameters of the ISO 13790 monthly method by reflecting the surface-to-volume $(\mathrm{S} / \mathrm{V})$ ratio and the characteristics of the structures. The calculation process was established, and the parameters necessary to derive the reference numerical parameters were calculated based on the input data prepared for the established calculation processes. The reference numerical parameters were then derived through regression analyses of the calculated parameters and the time constant. The parameters obtained from an apartment building and the parameters of the international standard were both applied to the Passive House Planning Package (PHPP) and EnergyPlus programs, and the results were analyzed in order to evaluate the validity of the results. The analysis revealed that the calculation results based on the parameters derived from this study yielded lower error rates than those based on the default parameters in ISO 13790. However, the differences were shown to be negligible in the case of high heat capacity.
\end{abstract}

Keywords: ISO13790; surface-to-volume ratio; monthly method; utilization factor; reference numerical parameters 


\section{Introduction}

In response to extreme weather conditions generated by greenhouse gases, many global efforts are currently underway to reduce the energy consumption in buildings. Because of the long life cycle of buildings compared to other sectors and due to the difficulty in modifying the design once construction begins, it is necessary to carry out a quantitative analysis at the design stage by considering the items affecting the building's energy performance. The energy performance of a building is analyzed via simulations using static or dynamic methods. In static methods, energy is analyzed under the assumption that temperature is in a steady state regardless of time flow. Although the analytic process of the static methods is simple, high accuracy cannot be expected. In dynamic methods, on the contrary, timedependent temperature changes are reflected in the analysis, i.e., the energy of a building is analyzed in an unsteady state. While the dynamic analysis can produce more precise performance analysis than a static analysis, its drawback is that only a small number of experts can perform such an analysis, because of the difficulty associated with program application.

ISO 13790 [1] is an international standard that specifies methods of analyzing energy, which reflects the dynamic properties of a building under the steady-state condition. The standard involves a simple calculation process of deriving relatively accurate performance analysis results, and thus, it enables more convenient energy performance analysis than simulation tools. Many countries have established ISO 13790-based standard references, including SAP (Standard Assessment Procedure) [2] in the United Kingdom, PN ISO EN 13790 in Poland, the National Building Code [3] in Finland, KENAK

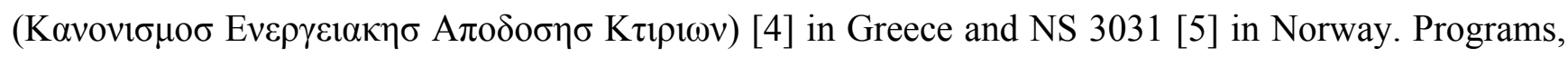
such as PHPP [6], have also been developed. In South Korea, programs, e.g., ECO2 [7], CE3 (Construction Energy-Efficiency-Evaluation) [8] and BESS (Building Energy Simulation for Seoul) [9], based on ISO 13790, have been developed and are being used in building energy rating systems and in the calculation of the total energy consumption of buildings. According to ISO 13790, the energy performance of buildings is calculated by applying the reference numerical parameters $\left(\alpha_{0}, \tau_{0}\right)$. If a country does not have specified reference numerical parameters, default values $\left(\alpha_{0}=1, \tau_{0}=15\right)$ proposed in ISO 13790 are used. Most Korean programs based on the algorithm of ISO 13790 apply the values of $\alpha_{0}=1$ and $\tau_{0}=15$. These values, however, do not reflect the local climatic conditions and the characteristic features of buildings, and many studies [10-15] have been conducted to determine the reference numerical parameters appropriate for an individual country. Jokisalo et al. [10] determined the reference numerical parameter values appropriate for the climate in Finland. Panek et al. [11] classified parameters suitable for the Polish climate into light-weight or heavy-weight buildings. Le Dreau et al. [12] classified Danish climatic conditions into the heating season and cooling season and obtained the values of $\alpha_{0}=2.87, \tau_{0}=47$ and $\alpha_{0}=2.79, \tau_{0}=35$, respectively. Corrado et al. [13] applied both reference numerical parameters and the window-to-wall ratio $(\xi)$, which is a design factor of a building, to the Italian climatic conditions. The results in all of the different countries confirm that reference numerical parameters derived in each country can vary widely and that country-specific reference numerical parameters can also be obtained by additionally considering the design factors of buildings.

The aim of this study is to derive the reference numerical parameters by applying the surface-to-volume $(\mathrm{S} / \mathrm{V})$ ratio to the envelope area, which is a design factor for buildings, and the characteristic features of the building structure. First, a theoretical equation related to the monthly 
method of ISO 13790 was reviewed to understand the concept of the reference numerical parameters and to obtain the reference numerical values and a coefficient of the $\mathrm{S} / \mathrm{V}$ ratio. To develop a method for deriving the reference numerical parameters, the basic calculation system and the range of the reference numerical parameters were established by examining the calculation processes proposed in existing international standards and studies. On the basis of the established basic calculation system and range, we established a five-stage calculation process. Input data required for each process were prepared by analyzing the main input conditions specified by the analytic tools according to the calculation process. Using these data, the variables needed to find the reference numerical parameters and the coefficient of the $\mathrm{S} / \mathrm{V}$ ratio were calculated, followed by regression analysis on the calculated variables. In addition, the validity of the parameters, which were derived by using an actual building reflecting the characteristics of apartment buildings as a target building, was evaluated by comparing the error rates of the results calculated with a quasi-steady-state program and a dynamic program with those of the results calculated by applying the international standard values.

\section{Review of Previous Studies on the Reference Numerical Parameters in ISO 13790}

\subsection{Processes of Calculating Gain and Loss Utilization Factor}

The gain and loss utilization factor can have different meanings depending on the season, e.g., heating or cooling. The gain utilization factor refers to the degree of utilizing the total heat gain to reduce the total heat loss, whereas the loss utilization factor refers to the degree of utilizing the total heat loss to reduce the total heat gain. In other words, the gain utilization factor is a coefficient used to prevent energy demand from being overestimated by reflecting the effects of overheating on the calculation of the energy needed for heating. The loss utilization factor relates to the utilization of total heat transfer through an envelope and ventilation to reduce the energy need for cooling during the cooling season. The unused heat transfer is generated at night, which leads to the calculation of the excessive energy needed for cooling, because it is reflected in the process of calculating the energy needed for cooling, although it does not affect the energy needed for cooling in the daytime. The loss utilization factor is used as a coefficient to prevent this overestimation of cooling energy. The reference numerical parameters and the time constant during the heating and cooling seasons are defined by Equations (1)-(10), and the values indicated in Table 1 are applied when country-specific values are absent.

$$
\begin{gathered}
\Upsilon_{H}=\frac{Q_{H, g n}}{Q_{H, h t}} \\
\Upsilon_{H}>0 \text { and } \Upsilon_{H} \neq 1: \eta_{H, g n}=\frac{1-\Upsilon_{H}^{\alpha_{H}}}{1-\gamma_{H}^{\alpha_{H}+1}} \\
\Upsilon_{H}=1: \eta_{H, g n}=\frac{\alpha_{H}}{\alpha_{H}+1} \\
\Upsilon_{H}<0: \eta_{H, g n}=\frac{1}{\Upsilon_{H}} \\
\alpha_{H}=\alpha_{H, 0}+\frac{\tau}{\tau_{H, 0}}
\end{gathered}
$$




$$
\begin{gathered}
\Upsilon_{C}=\frac{Q_{C, g n}}{Q_{C, h t}} \\
\Upsilon_{C}>0 \text { and } \Upsilon_{C} \neq 1: \eta_{C, l s}=\frac{1-\Upsilon_{C}^{-\alpha_{C}}}{1-\gamma_{C}^{-\left(\alpha_{C}+1\right)}} \\
\Upsilon_{C}=1: \eta_{C, l s}=\frac{\alpha_{C}}{\alpha_{C}+1} \\
\Upsilon_{C}<0: \eta_{C, l s}=\frac{1}{\Upsilon_{C}} \\
\alpha_{C}=\alpha_{C, 0}+\frac{\tau}{\tau_{C, 0}}
\end{gathered}
$$

Table 1. Numerical parameter and reference time constant of ISO 13790.

\begin{tabular}{ccc}
\hline Type of Method & $\boldsymbol{\alpha}_{\mathbf{H}, \mathbf{0}, \boldsymbol{\alpha}_{\mathbf{C}, \mathbf{0}}}$ & $\boldsymbol{\tau}_{\mathbf{H}, \mathbf{0}, \boldsymbol{\tau}_{\mathbf{C}, \mathbf{0}}}$ \\
\hline Monthly method & 1 & 15 \\
\hline
\end{tabular}

The time constant, which indicates the thermal inertia of building structures, is calculated using the heat capacity directly acting on the interior, the heat transfer coefficient by transmission and the heat transfer coefficient by ventilation among the factors acting on the air-conditioning space.

In Equation (12), $C_{m}$ denotes the heat capacity of the building elements. The effective thickness, $d T$, in this context means the minimum value among half of the total thickness of the component, the thickness of materials between the surface of interest and the first thermal insulating layer and a maximum effective thickness of $0.1 \mathrm{~m}$ for a one-day period of the variation as specified in the simplified calculation of the heat capacity of ISO 13786 Annex A [16]. When all of the elements, such as internal walls, are included in the internal space, the maximum effective thickness equals the total thickness between the two surfaces of the wall.

$$
\begin{gathered}
\tau=\frac{C_{m} / 3600}{H_{t r, a d j}+H_{v e, a d j}} \\
C_{m}=\sum\left(k_{j} A_{j}\right) \\
k_{j}=\sum_{i} \rho_{i} d_{i} c_{i} \\
\sum_{i} d_{i}=d_{T}
\end{gathered}
$$

\subsection{Review of Previous Studies on Deriving the Reference Numerical Parameters}

Jokisalo et al. [10] proposed $\alpha_{0}=2$, and $\tau_{0}=10$ as the reference numerical parameter values appropriate for Finnish climatic conditions. They also calculated the energy needed for heating by applying the derived values and the international standard value to the EN 13790 calculation process, and they compared the calculated results with the results of the IDA Indoor Climate and Energy (ICE) simulation. It was shown that the calculation results applying the international standard value were $40 \%$ 
different compared to the IDA ICE simulation; while the calculation results applying the derived parameter results were only $7 \%$ different.

Corrado et al. [13] proposed the reference numerical parameters of ISO 13790 appropriate for the Italian climate in two categories depending on whether the window-to-wall ratio is considered or not. In this study, parameters were derived by calculating the variables required for calculating the loss utilization ratio using the dynamic simulation program targeting detached houses, apartment buildings and office buildings, followed by deriving the reference numerical parameters of the loss utilization ratio through regression analysis. Furthermore, in order to additionally apply the coefficient of the window-to-wall ratio, a CEN-standard office building with a different window-to-wall ratio was selected, and multiple regression analysis was performed. The values of the reference numerical parameters and the coefficient of the window-to-wall ratio obtained through the process described above are $\alpha_{0}=8.1, \tau_{0}=17$ and -13 , respectively. It was stated in this study that highly reliable results can be obtained even through a quasi-steady-state method if the reference numerical parameter is determined precisely. It was proposed that it is necessary to investigate thermal effects between air-conditioning systems and buildings and to evaluate the average efficiency of other components in order to apply this method to calculate the main energy demand.

Panek et al. [11] derived the reference numerical parameters of lightweight and heavyweight apartments appropriate for Polish climatic conditions as $\alpha_{0}=2, \tau_{0}=54$ and $\alpha_{0}=2, \tau_{0}=50$, respectively. The results of calculating the heating and cooling energy consumption applying the derived parameters were compared with the results obtained using the TRNSYS program to evaluate the validity of the derived parameters. As a result, the error rates of the results of calculating the energy consumption applying the derived parameters and the TRNSYS program were $4.6 \%$ during the heating season and $2.4 \%$ during the cooling season, showing that the error rates concerning the heating and cooling energy consumption increased by $1.1 \%$ and decreased by $5.7 \%$, respectively, compared with those calculated by applying the values specified by the international standards. With regards to heavyweight apartment buildings, error rates of $3.4 \%$ and $1.7 \%$ occurred during the heating and cooling seasons, respectively, showing that the error rates in the heating and cooling energy consumption increased by $0.4 \%$ and decreased by $10.8 \%$ respectively, compared with those of the results calculated applying the values specified by the international standards. These results verify that the error rates for calculating the cooling energy consumption decreased when the derived parameters were applied.

Le Dreau et al. [12] determined the reference numerical parameter values and the coefficient of the window-to-wall ratio appropriate for the Danish climate to be $\alpha_{0}=2.87$ and $\tau_{0}=47$ for the heating season and $\alpha_{0}=2.79, \tau_{0}=35$ and $\xi_{0}=2.69$ for the cooling season, respectively. They also compared the error rates of calculation results obtained by applying the derived parameters and the dynamic-state program with those obtained by applying the parameters specified in the international standards. The comparison results confirmed that the error rates of the former increased by $0.7 \%$ during the heating season and decreased by $4.3 \%$ during the cooling season compared with those of the latter, thus demonstrating that the error rate during the cooling season can be reduced by applying the derived parameter. 
Table 2 summarizes the reference numerical parameter values derived for each country on the basis of the monthly method of ISO 13790.

Table 2. Reference numerical parameters used in EU countries.

\begin{tabular}{|c|c|c|c|}
\hline Country & $\begin{array}{c}\text { Reference Numerical } \\
\text { Parameter }\end{array}$ & Regression Equation & Notes \\
\hline Finland & $\alpha_{\mathrm{H}(\mathrm{C}), 0}=2, \tau_{\mathrm{H}(\mathrm{C}), 0}=10$ & $\alpha_{\mathrm{H}(\mathrm{C})}=2+\tau / 10$ & $\begin{array}{l}\text { Light-weight, medium-weight and } \\
\text { heavy-weight apartments }\end{array}$ \\
\hline Italy & $\begin{array}{l}\alpha_{\mathrm{C}, 0}=6.3, \tau_{\mathrm{C}, 0}=17 \\
\alpha_{\mathrm{C}, 0}=8.1, \tau_{\mathrm{C}, 0}=17\end{array}$ & $\begin{array}{c}\alpha_{C}=6.3+\tau / 17 \\
\alpha_{C}=8.1+\tau / 17-13 \xi\end{array}$ & Window-to-wall ratio \\
\hline Poland & $\begin{array}{c}\text { Light-weight: } \\
\alpha_{\mathrm{H}(\mathrm{C}), 0}=2, \tau_{\mathrm{H}(\mathrm{C}), 0}=54 \\
\text { Heavy-weight: } \\
\alpha_{\mathrm{H}(\mathrm{C}), 0}=2, \tau_{\mathrm{H}(\mathrm{C}), 0}=50\end{array}$ & $\begin{array}{c}\text { Light-weight: } \\
\alpha_{\mathrm{H}(\mathrm{C})}=2+\tau / 54 \\
\text { Heavy-weight: } \\
\alpha_{\mathrm{H}(\mathrm{C})}=2+\tau / 50\end{array}$ & $\begin{array}{l}\text { Light-weight and } \\
\text { heavy-weight apartments }\end{array}$ \\
\hline Denmark & $\begin{array}{l}\alpha_{\mathrm{H}, 0}=2.87, \tau_{\mathrm{H}, 0}=47 \\
\alpha_{\mathrm{C}, 0}=2.79, \tau_{\mathrm{C}, 0}=35\end{array}$ & $\begin{array}{c}\alpha_{H}=2.87+\tau / 47 \\
\alpha_{C}=2.11+\tau / 35-2.69 \xi\end{array}$ & $\begin{array}{l}\text { Light-weight, medium-weight and } \\
\text { heavy-weight office buildings }\end{array}$ \\
\hline
\end{tabular}

\section{Establishment of Input Variables to Calculate the Reference Numerical Parameters}

\subsection{Model Building}

The basic calculation system and range of the reference numerical parameters were established by examining the methods of calculating the reference numerical parameters proposed in the international standard of ISO 13790 and in the studies [10-15,17]. Based on the basic calculation system, the reference numerical parameters were calculated in three steps: (i) preparation of the same meteorological data; (ii) derivation of the reference numerical parameters; and (iii) evaluation of validity.

A model building was chosen to calculate the reference numerical parameters considering heating and cooling energy performance that varies depending on the location of the target households in the apartment buildings. A building of two households consisting of two air-conditioning spaces and a core was defined as a unit module of the model building, and a virtual apartment house consisting of 12 households was established based on this unit module. Tables 3-5 summarize the key features of the model building and the material properties of the components of the heat transmission coefficient, and Figure 1 illustrates the unit module of the model building.

Table 3. Model building description.

\begin{tabular}{cc}
\hline Location & Republic of Korea (Seoul) \\
\hline Direction & South \\
Building use & Apartment building \\
Unit floor area $\left(\mathrm{m}^{2}\right)$ & 84 \\
Core floor area $\left(\mathrm{m}^{2}\right)$ & 16 \\
Height $(\mathrm{m})$ & 2.3 \\
\hline
\end{tabular}


Table 4. Thermal transmittance of the model building.

\begin{tabular}{ccc}
\hline & Area on Surface & Thermal Transmittance $\left(\mathbf{W} / \mathbf{m}^{\mathbf{2}} \mathbf{K}\right)$ \\
\hline & Roof & 0.18 \\
\hline \multirow{2}{*}{$\begin{array}{c}\text { External } \\
\text { walls }\end{array}$} & Near to outdoor air & 0.27 \\
\cline { 2 - 3 } & Near to semi-outdoor air & 0.37 \\
\hline & Internal wall & - \\
\hline & Floor & 0.81 \\
\hline & Lowest floor & 0.35 \\
\hline & Window & 1.5 \\
\hline
\end{tabular}

Table 5. Material properties of the envelope.

\begin{tabular}{ccccc}
\hline Material & $\begin{array}{c}\text { Density } \\
\left(\mathbf{k g} / \mathbf{m}^{\mathbf{3}}\right)\end{array}$ & $\begin{array}{c}\text { Specific Heat } \\
\mathbf{( J / k g K )}\end{array}$ & $\begin{array}{c}\text { Thermal } \\
\text { Conductivity } \\
\mathbf{( W / m})\end{array}$ & $\begin{array}{c}\text { Thermal } \\
\text { Resistance } \\
\left(\mathbf{m}^{2} \mathbf{K} / \mathbf{W}\right)\end{array}$ \\
\hline Unreinforced concrete & 2200 & 879 & 0.06 & - \\
Concrete & 2240 & 879 & 1.6 & - \\
Autoclave light-weight concrete & 650 & 1173 & 0.13 & - \\
Gypsum board & 940 & 1130 & 0.18 & - \\
Cement mortar & 1950 & 921 & 1.4 & - \\
Extruded polystyrene form insulation & 35 & 1400 & 0.027 & - \\
Air layer & - & - & - & 0.086 \\
\hline
\end{tabular}

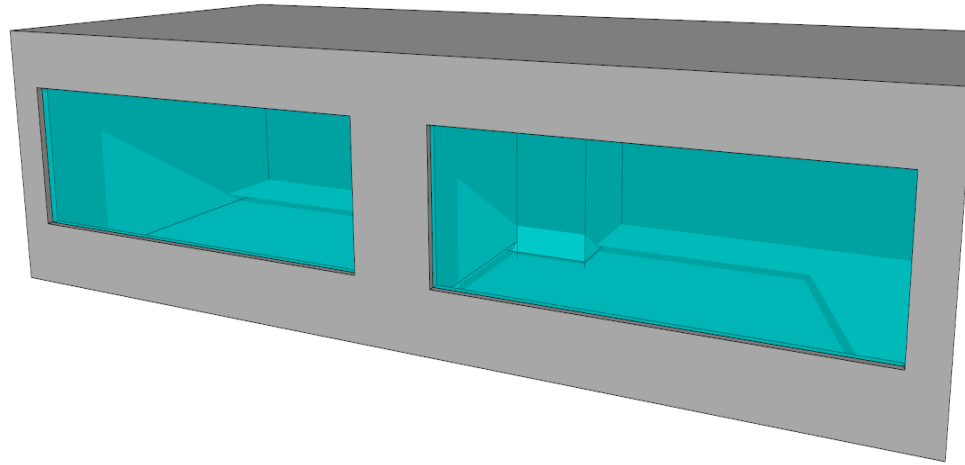

Figure 1. Unit module of the model building.

\subsection{Establishment of Input Data in the Analysis Program}

EnergyPlus is a dynamic program used for comparison in this study, and PHPP was used as a calculation tool to derive the reference numerical parameters. The pre-set heating and cooling temperatures of the model building, conditions related to indoor heat values and operation schedules for room occupancy, lighting, electric devices and cooling and heating, were established on the basis of existing standards and previous studies. The pre-set heating and cooling temperatures of the model building were set based on the Building Design Code for Energy Saving [18], and indoor heat values were determined in accordance with the standards of ASHRAE (American Society of Heating, Refrigerating and Air Conditioning Engineers) Fundamentals [19]. The number of occupants in the model building was set as four per household based on the area of the exclusive use space of the 
apartment buildings. The infiltration rate and the ventilation rate estimated in the previous study [20] were revised and used where necessary. The selected input data are listed in Table 6.

Table 6. Input data for the model building.

\begin{tabular}{cc}
\hline & Input Data \\
\hline Heating set-point temperature & $20^{\circ} \mathrm{C}$ \\
Cooling set-point temperature & $26^{\circ} \mathrm{C}$ \\
Number of occupants & 4 persons \\
Internal heat gain: person & $115 \mathrm{~W} / \mathrm{m}^{2}$ \\
Internal heat gain: equipment & $7 \mathrm{~W} / \mathrm{m}^{2}$ \\
Internal heat gain: lighting & $5.4 \mathrm{~W} / \mathrm{m}^{2}$ \\
Natural infiltration rate & 0.3 Air Change per Hour \\
Ventilation rate & 0.7 Air Change per Hour \\
\hline
\end{tabular}

\section{Derivation of Gain and Loss Utilization Factors and Validity Evaluation}

Seoul, which represents a warm climate, was selected as the target region for the analysis. The data, which are in the epw file format, provided by the Korea Solar Energy Society, were used as meteorological data required for the analysis. Meteorological data are represented in an epw file format in the EnergyPlus program, which provides meteorological elements, such as dry-bulb temperature, dew point temperature, atmospheric pressure, horizontal global solar radiation, direct normal solar radiation and horizontal diffuse solar radiation for $8760 \mathrm{~h}$. On the other hand, the PHPP program uses a method of directly inputting meteorological elements required for analysis instead of meteorological data of a certain file. Meteorological elements that should be defined in this program include monthly average dry-bulb temperature, dew point temperature, air temperature, earth temperature, horizontal global solar radiation and solar radiation on the vertical surfaces along certain directions, which are defined in the same way as shown in the epw file. The climate data for PHPP is illustrated in Figure 2.

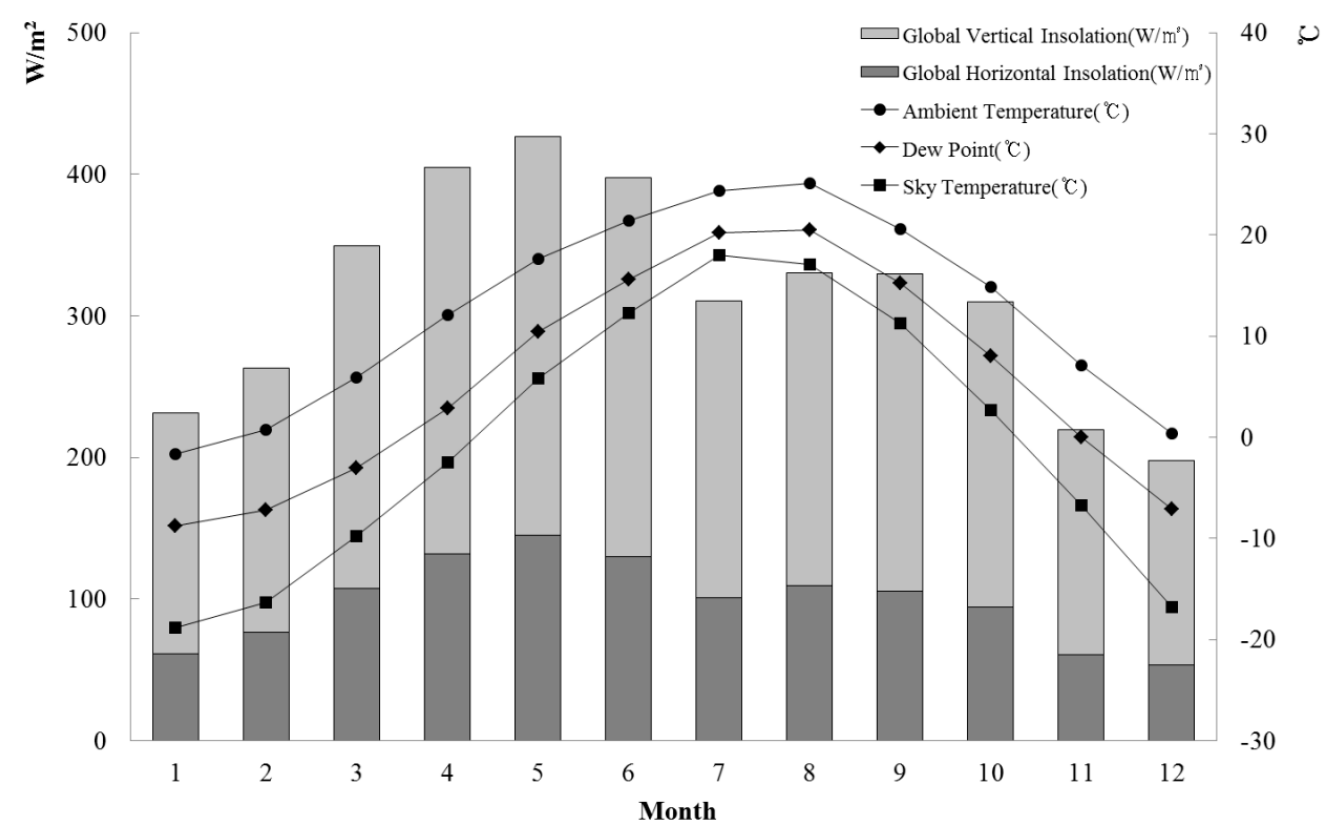

Figure 2. Climate data in Seoul, Korea. 


\subsection{Simulation Case}

A case was constructed by increasing the density and specific heat of an internal wall at a steady rate to establish the parameters and time constant as variables of the reference numerical parameters. The density, specific heat and thickness are the elements that are applied to the calculation of the heat capacity of buildings. The thickness refers to the maximum effective thickness. However, when the heat capacity is calculated applying the maximum effective thickness, the heat capacity of external walls, roofs, floors and side walls, except internal walls, are always calculated equally, regardless of changes in material properties. For this reason, the variables of the reference numerical parameters cannot be established. Thus, the case was formed based on the material properties of internal walls that facilitate variable setting, as shown in Table 7.

Table 7. Input data for the model building. S/V, surface-to-volume ratio.

\begin{tabular}{|c|c|c|c|c|c|c|}
\hline \multirow[t]{2}{*}{ Case } & \multirow{2}{*}{$\begin{array}{l}\text { Density of Internal } \\
\text { Wall }\left(\mathrm{kg} / \mathrm{m}^{2}\right)\end{array}$} & \multirow{2}{*}{$\begin{array}{c}\text { Specific Heat of } \\
\text { Internal Wall }(\mathrm{J} / \mathrm{kgK})\end{array}$} & \multicolumn{4}{|c|}{$\begin{array}{c}\text { Heat Value of S/V Ratio } \\
\left(\text { Wh/K Pro } \text { m }^{2} \text { Treated Floor Area) }\right.\end{array}$} \\
\hline & & & 1.023 & 0.608 & 0.483 & 0.397 \\
\hline Case 1 & 1280 & 840 & 46 & 85 & 121 & 215 \\
\hline Case 2 & 1440 & 850 & 48 & 88 & 125 & 219 \\
\hline Case 3 & 1600 & 860 & 49 & 91 & 129 & 223 \\
\hline Case 4 & 1760 & 870 & 51 & 94 & 133 & 227 \\
\hline Case 5 & 1920 & 880 & 53 & 97 & 136 & 232 \\
\hline Case 6 & 2080 & 890 & 55 & 100 & 141 & 236 \\
\hline Case 7 & 2240 & 900 & 56 & 103 & 145 & 241 \\
\hline
\end{tabular}

\subsection{Calculation of Variables Related to the Reference Numerical Parameters}

Using EnergyPlus in accordance with the calculation process for deriving the reference numerical parameters as specified in Tables 8 and 9, we calculated the loss and gain amounts according to the placement types of the model building, the energy need, utilization factors and the heat-balance ratios depending on heating and cooling seasons.

Table 8. Input condition and output data for the reference numerical parameters.

\begin{tabular}{|c|c|c|c|c|c|c|}
\hline \multirow{2}{*}{ Season } & \multicolumn{5}{|c|}{ Input Condition } & \multirow{2}{*}{ Output Data } \\
\hline & HVAC Type & Set-Temperature & Solar Radiation & Space Load & Ventilation & \\
\hline \multirow{3}{*}{ Heating } & Single H/C & & $\times$ & $\times$ & 0 & $Q_{H_{1}}^{\text {set.20 }}, Q_{C_{1}}^{\text {set.20 }}$ \\
\hline & Single $\mathrm{H} / \mathrm{C}$ & $20^{\circ} \mathrm{C}$ & O & O & O & $Q_{H_{2}}^{\text {set.20 }}, Q_{C_{2}}^{\text {set.20 }}$ \\
\hline & Dual H/C & & O & O & O & $Q_{H_{3}}^{\text {set.20 }}$ \\
\hline \multirow{3}{*}{ Cooling } & Single H/C & & $x$ & $x$ & O & $Q_{H_{1}}^{\text {set.26 }}, Q_{C_{1}}^{\text {set.26 }}$ \\
\hline & Single $\mathrm{H} / \mathrm{C}$ & $26{ }^{\circ} \mathrm{C}$ & O & O & O & $Q_{\mathrm{H}_{2}}^{\text {set.26}}, Q_{C_{2}}^{\text {set.26 }}$ \\
\hline & Dual H/C & & 0 & O & ○ & $Q_{C_{3}}^{\text {set.26 }}$ \\
\hline
\end{tabular}

H/C, Heating and Cooling system; ×, unapplied; ○, applied. 
Table 9. Parameter formulas of the gain and loss utilization factor.

\begin{tabular}{ccc}
\hline & Heating Season & Cooling Season \\
\hline Heat loss & $Q_{H, h t}=Q_{H_{1}}^{\text {set.20 }}-Q_{C_{1}}^{\text {set.20 }}$ & $Q_{C, h t}=Q_{H_{1}}^{\text {set.26 }}-Q_{C_{1}}^{\text {set.26 }}$ \\
Heat gain & $Q_{H, g n}=Q_{H, h t}-\left(Q_{H_{2}}^{\text {set.20 }}-Q_{C_{2}}^{\text {set } 20}\right)$ & $Q_{C, g n}=Q_{C, h t}-\left(Q_{H_{2}}^{\text {set.26 }}-Q_{C_{2}}^{\text {set.26 }}\right)$ \\
Energy need & $Q_{H, n d}=Q_{H_{3}}^{\text {st.20 }}$ & $Q_{C, n d}=Q_{C_{3}}^{\text {set.26 }}$ \\
Utilization factor & $\eta_{H, g n}=\left(Q_{H, h t}-Q_{H, n d}\right) / Q_{H, g n}$ & $\eta_{C, l s}=\left(Q_{C, g n}-Q_{C, n d}\right) / Q_{C, h t}$ \\
Heat-balance ratio & $\gamma_{H}=Q_{H, g n} / Q_{H, h t}$ & $\gamma_{C}=Q_{C, g n} / Q_{C, h t}$ \\
\hline
\end{tabular}

\subsection{Calculation of the Reference Numerical Parameters and the Time Constant}

In Figure 3, the reference numerical parameters are obtained as follows: the utilization factors and the heat-balance ratio during heating and cooling seasons, which are calculated above, are applied to Equations (2) and (7) to obtain the monthly reference numerical parameters. The average values of the monthly reference numerical parameters for the heating season (November to April) and of the cooling season (May to October) [21] are calculated separately and established as the reference numerical parameters of each case; the time constant is obtained by applying the heat capacity and heat transfer coefficient by transmission to Equation (11).
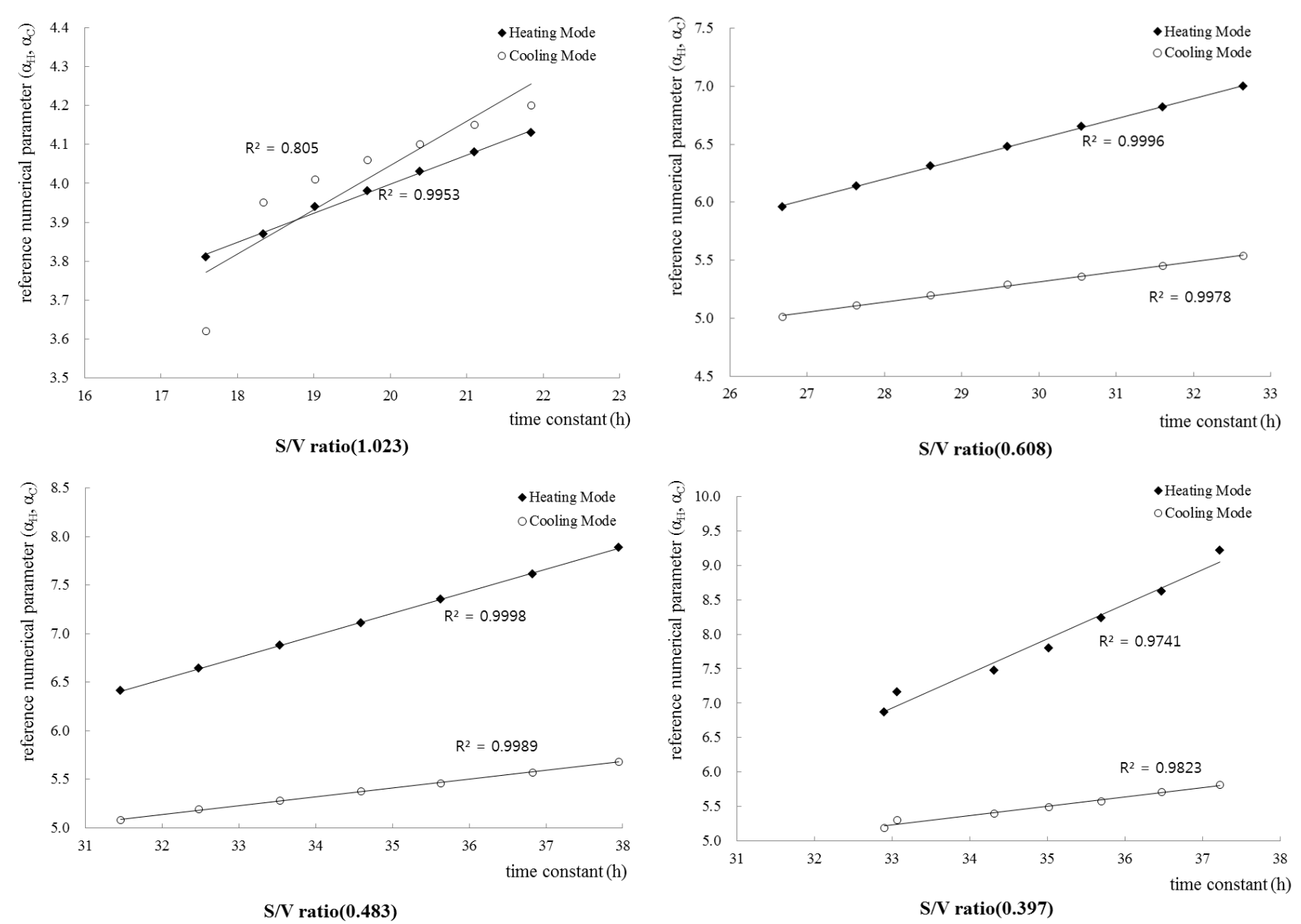

Figure 3. Time constant and numerical parameters according to the $\mathrm{S} / \mathrm{V}$ ratio. 


\subsection{Derivation of the Reference Numerical Parameters through Regression Analysis}

The reference numerical parameters were derived in the cases of considering and not considering the coefficient of the $\mathrm{S} / \mathrm{V}$ ratio $(\beta=0$ and $\beta \neq 0$, respectively), followed by regression analysis of the parameter and time constant shown in Figure 3. A regression equation was established based on the derived reference numerical parameters, as presented in Table 10. As indicated in this table, the coefficient of determination of the regression equation is 0.9 or greater, showing a high goodness of fit of the regression equation. It is considered that the regression equation obtained in this study can be effectively used to estimate the reference numerical parameters of other apartment buildings.

Table 10. Regression equations of heating and cooling seasons with or without the S/V ratio.

\begin{tabular}{ccccccc}
\hline \multirow{2}{*}{ Season } & $\begin{array}{c}\text { S/V } \\
\text { Ratio }(\boldsymbol{\beta})\end{array}$ & $\boldsymbol{\alpha}_{0}$ & $\boldsymbol{\tau}_{\mathbf{0}}$ & $\boldsymbol{\beta}$ Coefficient & $\mathbf{R}^{\mathbf{2}}$ & Regression Equation \\
\hline \multirow{2}{*}{ Heating } & $\beta=0$ & 0.62 & 4.25 & - & 0.969 & $\alpha_{\mathrm{H}}=0.62+\tau / 4.25$ \\
& $\beta \neq 0$ & 14.77 & 10.03 & -8.66 & 0.999 & $\alpha_{\mathrm{H}}=14.747+\tau / 10.03-8.66 \beta$ \\
\hline \multirow{2}{*}{ Cooling } & $\beta=0$ & 2.23 & 10.57 & - & 0.940 & $\alpha_{\mathrm{C}}=2.23+\tau / 10.57$ \\
& $\beta \neq 0$ & 7.95 & 33.42 & -3.22 & 0.966 & $\alpha_{\mathrm{C}}=7.95+\tau / 33.42-3.22 \beta$ \\
\hline
\end{tabular}

\section{Validity Evaluation of the Reference Numerical Parameters}

\subsection{Key Features of the Target Apartment Buildings for Evaluation}

The target apartment buildings for evaluation were defined in compliance with the standard house for evaluation, as specified in the Green Home Design and Performance Evaluation Guideline [22]. The target apartment was designed to have an expanded form, and its floor area and height were set to be $84 \mathrm{~m}^{2}$ and $2.3 \mathrm{~m}$, identical to those of the model building (Figure 4). The conditions of forming the envelope structure, windows and doors, as well as input conditions for analysis, in addition to the key features of the target apartment buildings for evaluation, were established to be identical to those of the aforementioned model building. In order to evaluate the validity of the reference numerical parameters depending on the heat capacity of the building, the placement of the target buildings for evaluation was divided into four types: 12X1, 6X2, 4X3 and 2X6.

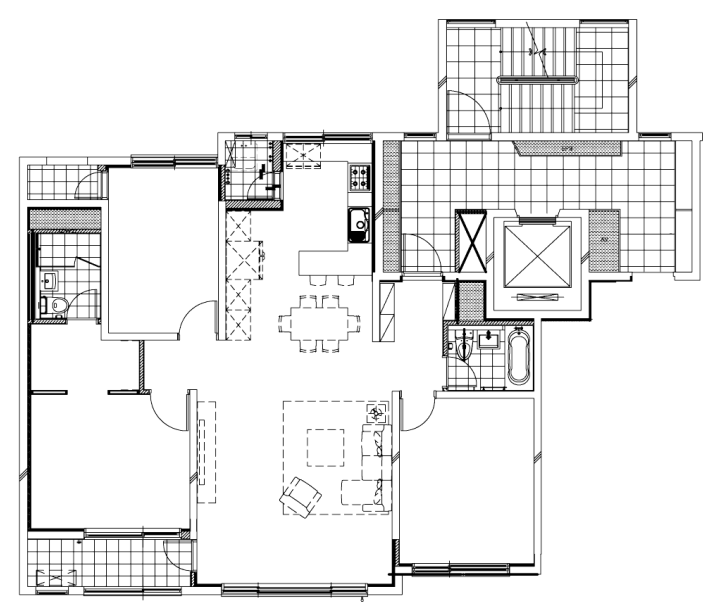

Figure 4. Floor plan of the apartment building. 


\subsection{Calculation of Parameters during Heating and Cooling Seasons through the Regression Equation}

When the coefficient of the $\mathrm{S} / \mathrm{V}$ ratio is not applied, the reference numerical parameters derived are applied to the PHPP program. On the contrary, when the coefficient of the S/V ratio is applied, the S/V ratio, number of hours (constant number) and the derived reference numerical parameters are applied to the regression equation to calculate the parameters during heating and cooling seasons, followed by the application of the calculated values to the PHPP program. The parameters of regression equation considering the $\mathrm{S} / \mathrm{V}$ ratio are listed in Table 11 .

Table 11. Parameters of regression equation considering the $\mathrm{S} / \mathrm{V}$ ratio.

\begin{tabular}{cccccc}
\hline Type & Heat Capacity $\left(\mathbf{W h} / \mathbf{K}\right.$ Pro $\mathbf{~ m}^{\mathbf{2}}$ TFA) & S/V Ratio & $\boldsymbol{\tau} \mathbf{( h )}$ & $\boldsymbol{\alpha}_{\mathbf{H}}$ & $\boldsymbol{\alpha}_{\mathbf{C}}$ \\
\hline 12X1 & 45 & 0.922 & 31.3 & 9.91 & 5.92 \\
6 X2 & 84 & 0.494 & 67.1 & 17.18 & 8.37 \\
4 X3 & 120 & 0.356 & 101.3 & 21.79 & 9.83 \\
2X6 & 216 & 0.233 & 192.1 & 31.90 & 12.95 \\
\hline
\end{tabular}

\subsection{Analysis of Energy Demand and Error Rates Using the Analysis Program}

To evaluate the validity of the derived reference numerical parameters, heating and cooling energy demands were calculated using EnergyPlus and PHPP, and error rates were analyzed to determine the degree of change in the calculation results depending on whether the derived parameters are applied or not. The evaluation results indicated that when the calculation was performed by applying the reference numerical parameters obtained in this study to all of the building placement types, the error rates were decreased with respect to the results of using EnergyPlus. The results of analyzing the extent of error rate reductions revealed that the error rates decreased, irrespective of whether or not the $\mathrm{S} / \mathrm{V}$ ratio was applied, more in the cooling energy demand. That is considered to be due to the greater effects of the reference numerical parameters on the cooling energy demand than on the heating one. The extent of the error rate reduction according to the placement types of the building was the greatest in the 12X1 type, in which the heat capacity is the lowest regardless of the coefficient of the $\mathrm{S} / \mathrm{V}$ ratio, and the lowest in the 2X6 type, which has the greatest heat capacity (Table 12 and Figure 5).

Table 12. Error rate of heating and cooling energy demands.

\begin{tabular}{|c|c|c|c|c|}
\hline \multirow{2}{*}{ Season } & \multirow{2}{*}{ Type } & \multicolumn{3}{|c|}{ Error Rate (\%) } \\
\hline & & DS and $\mathbf{S S}_{\mathrm{ref}}$ & DS and $\mathrm{SS}_{1}$ & DS and $\mathrm{SS}_{2}$ \\
\hline \multirow{4}{*}{ Heating } & $12 \times 1$ & 19.0 & $11.0(7.9 \downarrow)$ & $10.5(8.5 \downarrow)$ \\
\hline & $6 \times 2$ & 26.4 & $22.5(3.9 \downarrow)$ & $22.4(4.0 \downarrow)$ \\
\hline & $4 \times 3$ & 30.8 & $28.8(2.0 \downarrow)$ & $28.8(1.9 \downarrow)$ \\
\hline & $2 \times 6$ & 24.8 & $24.5(0.3 \downarrow)$ & $24.5(0.3 \downarrow)$ \\
\hline \multirow{4}{*}{ Cooling } & $12 \times 1$ & 25.2 & $7.0(18.2 \downarrow)$ & $5.3(19.9 \downarrow)$ \\
\hline & $6 \times 2$ & 16.7 & $11.0(5.7 \downarrow)$ & $12.0(4.7 \downarrow)$ \\
\hline & $4 \times 3$ & 8.7 & $6.0(2.6 \downarrow)$ & $7.6(1.1 \downarrow)$ \\
\hline & $2 \times 6$ & 7.1 & $6.3(0.7 \downarrow)$ & $6.3(0.7 \downarrow)$ \\
\hline
\end{tabular}

DS, calculation result of dynamic simulation (EnergyPlus); $\mathrm{SS}_{\text {ref, }}$ calculation result of quasi-steady-state simulation (PHPP) with the reference numerical parameter of ISO 13790; $\mathrm{SS}_{1}$, calculation result of quasi-steady-state simulation (PHPP) with proposed reference numerical parameters; $\mathrm{SS}_{2}$, Calculation result of quasi-steady-state simulation (PHPP) with proposed reference numerical parameters, S/V ratio. 

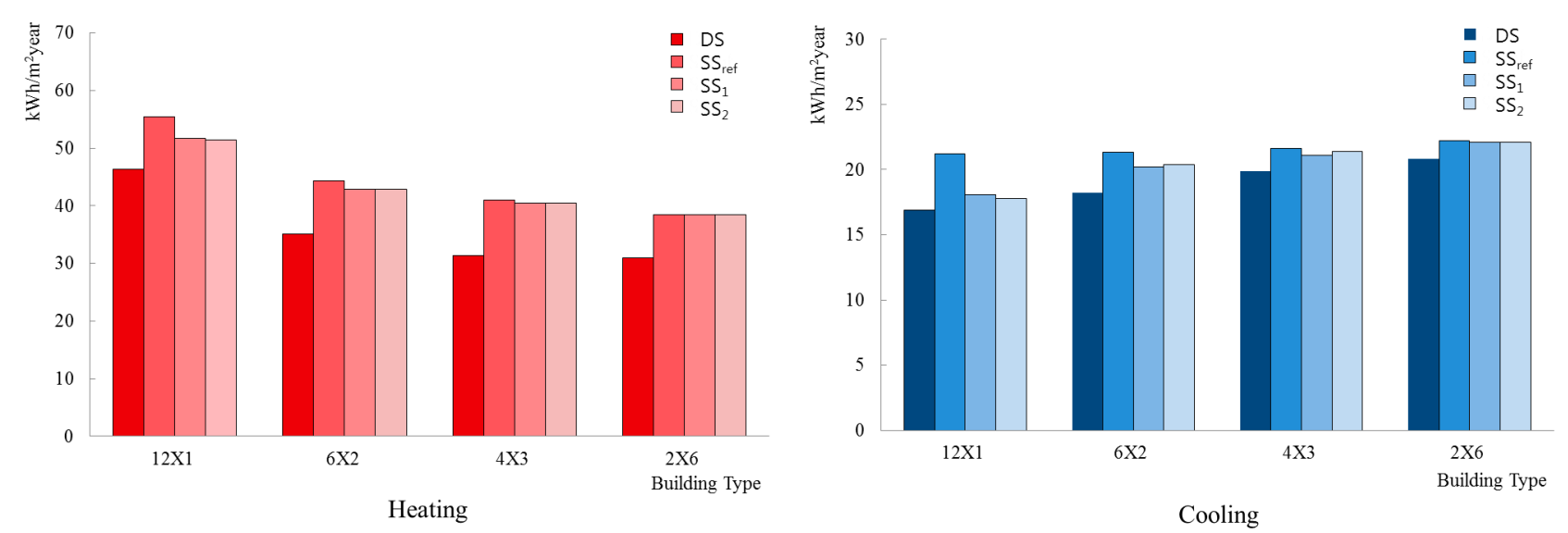

Figure 5. Energy needs according to building type.

\section{Conclusions}

The reference numerical parameters and the coefficient of the $\mathrm{S} / \mathrm{V}$ ratio were obtained by reflecting the $\mathrm{S} / \mathrm{V}$ ratio and the characteristics of the structures on apartment buildings.

The regression equation was established by additionally deriving the coefficient of the $\mathrm{S} / \mathrm{V}$ on the envelope area, which is a design factor of buildings related to the energy performance of buildings, besides the reference numerical parameters, and distinguishing between the cases of applying the coefficient of the $\mathrm{S} / \mathrm{V}$ ratio and not applying it. To evaluate the validity of the derived reference numerical parameters and the coefficient of the $\mathrm{S} / \mathrm{V}$ ratio, the heating and cooling energy needs of buildings reflecting the practical characteristics of apartment buildings through PHPP and EnergyPlus and the error rates of the calculation results were analyzed. Analytic results confirmed that the error rate of the results of applying the parameters derived in this study decreased more than the case where the parameters of ISO 13790 were applied, whereas a reduction in the error rate was insignificant when the heat capacity was great, as shown in the 2X6 type. Hence, it is required to apply additional coefficients related to parameters affecting the energy need, such as indoor heat values, the infiltration rate and the ventilation rate, in addition to the reference numerical parameters, or to conduct studies on deriving the reference numerical parameters considering the correction factors on the heat capacity of building structures. Furthermore, because the reference numerical parameters obtained in this study are based on apartment buildings in Seoul, meteorological conditions and structure characteristics are modified when target regions and building applications are adjusted, thereby reducing the accuracy of the calculation results applying the derived reference numerical parameters.

\section{Acknowledgments}

This research was supported by the Basic Science Research Program through the National Research Foundation of Korea (NRF) funded by the Ministry of Education (20120008012). 


\section{Author Contributions}

Hee-Jeong Kwak and Jae-Hun Jo had the original idea for the study, and all co-authors conceived of and designed the methodology. Hee-Jeong Kwak drafted the manuscript, which was revised by Jae-Hun Jo. All authors read and approved the final manuscript.

\section{Nomenclature}

$A_{j} \quad$ area of the element $j\left(\mathrm{~m}^{2}\right)$

$C_{m} \quad$ internal heat capacity of the building or building zone $(\mathrm{J} / \mathrm{K})$

$c_{i} \quad$ heat capacity of a layer $i(\mathrm{~J} / \mathrm{kgK})$

$d_{i} \quad$ thickness of a layer $i(\mathrm{~m})$

$k_{j} \quad$ areal heat capacity of the building element $j\left(\mathrm{~J} / \mathrm{m}^{2} \mathrm{~K}\right)$

\section{Greek Letters}

$\alpha_{C} \quad$ numerical parameter for the cooling mode, dimensionless

$\alpha_{C, 0} \quad$ reference numerical parameter for the cooling mode, dimensionless

$\alpha_{H} \quad$ numerical parameter for the heating mode, dimensionless

$\alpha_{H, 0} \quad$ reference numerical parameter for the heating mode, dimensionless

$\gamma_{H} \quad$ heat-balance ratio for the heating mode, dimensionless

$\gamma_{C} \quad$ heat-balance ratio for the cooling mode, dimensionless

$\tau \quad$ time constant of the building zone (h)

$\tau_{C, 0} \quad$ reference time constant for the cooling mode $(\mathrm{h})$

$\tau_{H, 0} \quad$ reference time constant for the heating mode $(\mathrm{h})$

$\rho_{i} \quad$ density of a layer $i\left(\mathrm{~kg} / \mathrm{m}^{3}\right)$

\section{Conflicts of Interest}

The authors declare no conflict of interest.

\section{References}

1. ISO. ISO 13790:2008 Energy Performance of Buildings-Calculation of Energy Use for Space Heating and Cooling; ISO: Geneva, Switzerland, 2008.

2. Standard Assessment Procedure (SAP). Available online: https://www.gov.uk/standardassessment-procedure (accessed on 2 December 2014).

3. National Building Code. Available online: http://www.ym.fi/en-us (accessed on 2 December 2014).

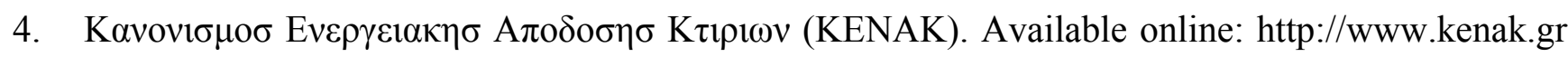
(accessed on 2 December 2014). (In Greek)

5. Norsk Standard. NS 3031:2014. Calculation of Energy Performance of Buildings-Method and Data; Standard Norway: Oslo, Norway, 2014.

6. Passive House Planning Package (PHPP). Available online: http://passiv.de (accessed on 2 December 2014). 
7. ECO2. Available online: http://www.kemco.or.kr (accessed on 2 December 2014).

8. Construction Energy-Efficiency-Evaluation (CE3). Available online: http://www.eco-ce3.kr (accessed on 2 December 2014).

9. Building Energy Simulation for Seoul (BESS). Available online: http://citybuild.seoul.go.kr (accessed on 2 December 2014).

10. Jokisalo, J.; Kurnitski, J. Performance of EN ISO 13790 utilisation factor heat demand calculation method in a cold climate. Energy Build. 2007, 39, 236-247.

11. Panek, A.; Rucińska, J.; Mijakowski, M. Adjustment of parameters used for calculation method applied in certification process in Poland. In Proceedings of the CESB10-Central Europe towards Sustainable Building, Prague, Czech, 30 June-2 July 2010.

12. Le Dreau, J.; Selman, A.D.; Heiselberg, P.; Jensen, R.L. Thermal Mass \& Dynamic Effects Danish Building Regulation; DCE Technical Reports, No. 152; Aalborg University: Aalborg, Denmark, 2013.

13. Corrado, V.; Fabrizio, E. Assessment of building cooling energy need through a quasi-steady state model: Simplified correlation for gain-loss mismatch. Energy Build. 2007, 39, 569-579.

14. Wauman, B.; Breesch, H.; Saelens, D. Evaluation of the accuracy of the implementation of dynamic effects in the quasi steady-state calculation method for school buildings. Energy Build. 2013, 65, 173-184.

15. Orosa, J.A.; Oliveira, A.C. Implementation of a method in EN ISO 13790 for calculating the utilisation factor taking into account different permeability levels of internal coverings. Energy Build. 2010, 42, 598-604.

16. ISO. ISO 13786:2011 Thermal Performance of Building Components-Dynamic Thermal Characteristics -Calculation Methods; ISO: Geneva, Switzerland, 2011.

17. Evangelisti, L.; Battista, G.; Guattari, C.; Basilicata, C.; de Lieto Vollaro, R. Influence of the Thermal Inertia in the European Simplified Procedures for the Assessment of Buildings' Energy Performance. Sustainability 2014, 6, 4514-4524.

18. Ministry of Land. Building Design Code for Energy Saving; Ministry of Land: Sejong City, Korea, 2012.

19. American Society of Heating, Refrigerating and Air Conditioning Engineers (ASHRAE). ASHRAE Handbook Fundamentals; ASHRAE: Atlanta, GA, USA, 2009.

20. Yoon, Y.S.; Yoon, J.H.; Hyun, J.H.; Hwang, W.J.; Shin, J.G.; Choi, W.K.; Mun, S.H. A Study on the Optimal Glazing Units in Apartment-Focused on the Glazing Performance and Heating/Cooling Setpoint Temperature. J. Archit. Instit. Korea 2012, 28, 301-308.

21. Kim, S.K. A Study on an Energy-Efficient Outdoor Air Supply Control Method in Apartment Ventilation System. Ph.D. Thesis, Dong-A University, Busan, Korea, 2009.

22. Ministry of Land. Green Home Design and Performance Evaluation Guideline; Ministry of Land, Sejong City, Korea, 2009.

(C) 2015 by the authors; licensee MDPI, Basel, Switzerland. This article is an open access article distributed under the terms and conditions of the Creative Commons Attribution license (http://creativecommons.org/licenses/by/4.0/). 